\title{
Why philosophy is important to medical ethics
}

Derek Parfit in his landmark Reasons and Persons ${ }^{1}$ asks us to imagine the following hypothetical case. You must have a very painful operation for which there is no anaesthesia. You will experience excruciating pain for several hours. But then you will be given a drug to induce amnesia. You will not remember any of the pain. You wake up in bed in hospital. Doctors come and say there has been a mistake. There are two patients due to have this procedure. They don't know if you were the patient who had this procedure done yesterday, or if you are the patient who must have this procedure today. They go away to try to find out which patient you are. Parfit claims that you have reason to hope you are the patient who had the procedure done yesterday.

While this was a hypothetical scenario written in 1984, there is a real life correlate of sorts. One problem in anaesthesia today is "awareness". This occurs when patients partially or fully wake during an operation. Sometimes, they cannot move or speak because they have been given a neuromuscular blocker, but they can hear, think, feel, and experience pain and fear. Some patients develop post-traumatic stress disorder because of the terrifying memory of this experience. If an anaesthetist becomes aware that the patient is aware, drugs like midazolam or propofol can be given to induce amnesia of the event, as in Parfit's example.

But how bad is past pain, even if we cannot remember it? It may be better than present or future pain, but is it nonetheless bad for a person? Should patients who experience such awareness be owed compensation? Should this possibility be discussed prior to surgery and the patient asked whether they wish to be given agents to induce amnesia. Such agents are routinely given when awareness is suspected. But what constitutes being conscious and aware? Does one need to merely feel pain or is the processing of information important, as Levy asks (see page 660)? If drugs are developed to erase memories after surgery, should these be given? Should they be offered to people who experience traumatic events, such as rape, car accidents or war? Or would this compromise the public interest in justice, a topic Kolber addresses (see page 658)?
These are deep philosophical questions which are addressed in the Feature Article, "Anesthesia, Amnesia and Harm" in this issue by Walter Glannon (see page 651), one of the pioneers of neuroethics, and a series of commentaries by leaders in neuroethics, neurolaw, philosophy and anaesthesia. This series shows just how important philosophy and ethics are to medicine. The question of what constitutes consciousness and awareness are, as Glannon and Levy show, philosophical questions. Once we have settled that, science can tell us how to measure it-but science alone cannot tell us what to look for. And how bad past but forgotten pain is, is another ethical issue. Davidson, in an excellent commentary, finishes, “Glannon's paper presents more questions than answers" (see page 659). It is the first job of good philosophy to raise questions. Many people believe these are purely technical, medical or scientific issues, but they are, as Davidson notes, ethical issues.

In general, what doctors should do depends both on science, but crucially on philosophy and ethics. For example, if forgotten pain is significantly better than future pain, in situations in which anaesthesia is risky, perhaps amnesia is better than anaesthesia. One answer is to leave it to patients to assess - but how can patients know how bad such events are if they have never experienced them, or never remember them?

The goals of the new Journal of Medical Ethics (JME) have been to retain the high quality empirical research published related to medical ethics, but also to increase the contribution of analytic philosophy and engagement with clinical practice. Glannon's Feature Article and associated commentaries are good examples of the contribution philosophy can make. This issue also contains a wealth of articles at the cutting edge of clinical practice.

In a more empirical but equally important contribution, Cummings, Diefenbach, and Mercurio discuss variation in practice around offering intestinal transplantation to the parents of infants who have short bowel syndrome, often as a result of the whole small intestine dying, a complication of prematurity (see page 665). This is a controversial procedure, with high mortality, and only $1 / 3$ of clinicians surveyed often or always offer it, even though more than 90\% thought parents should be offered the option. It seems as if there is a gap between what doctors say and what they do. In a thoughtful commentary, the world's best medical ethicist, Dominic Wilkinson, who is also a practicing neonatologist, describes this as a procedure in the "grey zone" (see page 671). As Cummings and colleagues suggest, better evidence will help. But such procedures will increase as medicine cuts new ground and Wilkinson notes and reflects on the difficulties of discussing such novel procedures with families in the age of the internet. As in the case of Glannon's article, sometimes precise recipes cannot be provided. The key to ethical medicine is not necessarily uniformity of practice, but being able to ethically justify one's own practice with reasons.

Buchman and Ho address the real and increasing problem of prescription opioid abuse (see page 673). They address the practice of opioid contracts: "formal and explicit written agreements between physicians and patients that delineate key aspects regarding adherence to opioid therapy". They argue that such contracts undermine trust and trustworthiness in the doctor patient relationship. While this article focuses on such contracts, it is a genuine contribution to an understanding of trust and "humility" in the doctorpatient relationship in general.

Continuing the engagement with clinical medicine, Magelssen, Pedersen and Førde offer provide a novel critique of clinical ethics, both clinical ethics committees and ethics consultants (see page 678). Such committees and ethicists have been well established in the US for several decades but are spreading throughout the world. They identify six kinds of bias and suggest methods to reduce bias. They argue that ethicists are more prone to such biases than committees. What is important, in the light of such work, is that clinical ethics be identified as a professional subspeciality with requirements for education, training and assessment. Because ethics is central to every person's life, every day, too often it is seen as a relativistic, culturally specific endeavor 
without a formal subject matter where everyone can be an expert. Having now spent more than 20 years as a full time professional in the field, the more I learn, the more I realise I have to learn.

Two articles address issues my team and I personally face. Wendler and Miller in "The ethics of peer review in bioethics" argue, in addition to an obligation to peer review, that peer review in bioethics ought to be double blind (see page 697). This is the current approach of the JME, though it is against the policy of our parent journal, the $B M J$. In fact, the editorial team of the JME has been debating, and is divided over, whether our policy should be triple-blinded, that is, editors blinded to the identity of contributors. There are arguments for and against; at present, editorial meetings and discussion of papers are generally conducted without knowledge of the author's identity.

In "Research funding and authorship: does grant winning count towards authorship credit?", Barton Moffatt deals with the perennial problem of what is sufficient to warrant authorship on academic publication (see page 683). This is an ever increasing problem, especially in interdisciplinary research between the sciences and humanities, where expectations and norms may differ. I remember when my first $\mathrm{PhD}$ student prepared her first publication, the director of our Institute (a scientific research institute) and also one of her supervisors, wished to be listed as a coauthor. She was reluctant. Although I had given her more assistance and comments, I came from discipline of philosophy and chose not to be a coauthor. Our director argued that he had won funding for her research, suggested the topic and had input into the paper and had approved the final version. $\mathrm{He}$ is an eminent scientist who has been Dean of a medical school. On Moffatt's argument, he deserved to be a coauthor. Such disagreements are common and our own practice now is to list explicitly expectations, including reference to international guidelines referred to by Moffatt, prior to commencing joint research. Perhaps the first step is for the relevant parties to agree on what the rules of their game will be, before they start playing.

In "Returning incidental findings from genetic research to children: views of parents of children affected by rare diseases", Erika Kleiderman and colleagues from Canada interviewed parents of children with rare disorders and found that "Parents believed they should be made aware of all results pertaining to their child's health status, and that they are responsible for transmitting this information to their child, irrespective of disease severity. Despite potential negative consequences, respondents generally perceived a favourable risk-benefit ratio in receiving all incidental findings" (see page 691). This is out of line with many professional guidelines and practices. While such studies do not by themselves establish that parents ought to be informed of such results, they do ask us to engage with and take seriously their reasons and arguments. I have myself written in the past arguing that there are non-medical reasons to provide predictive genetic testing to children, even when medical interventions are not available (Robertson and Savulescu, 2001). ${ }^{2}$

One of the objections to providing information, such as from predictive testing, to parents of children when no medical intervention is available is that this compromises the child's "right to an open future". Such arguments are often misplaced. What is really on offer is not the choice between a more open future or a less open future, but two mutually exclusive and different futures. This is best seen in the case of management of intersex conditions, such as androgen insensitivity syndrome, at birth. Historically, such children with ambiguous genitalia were assigned the female sex and female anatomy was surgically assigned. This had, supposedly, psychological benefits for parents and child, in the sense that the child was more easily able to be integrated into norms of the day. Parents and doctors feared the child would be teased, ostracized and suffer psychological harm if a definitive anatomical sex was not assigned. But later such children were denied the choice of choosing their own sex, or to remain intersex. In recent years, the open future argument has been wheeled out against early surgical intervention.

I have to confess, if my child was born with an intersex disorder, I would probably not choose to surgically assign a sex, having studied this issue a lot. But that is not because I think this gives the child a more open future. It is just that I believe there are various reasons that weigh against surgery. But as Dominic Wilkinson might put it, perhaps this is an area of medicine "in the grey zone". Other parents might legitimately and justifiably choose differently. Much of life involves making choices with no clearly dominant, right course. The challenge for all of us doctors, patients, parents and everyone is to actually make a choice (even if that is to do nothing) and to make these choices thoughtfully, on the basis of ethical reasons. Mercifully, we have the Journal of Medical Ethics to help us to do that.

I have enjoyed reading all the articles in this issue of the Journal (and I get increasingly cranky as I get older). I hope you do too.

\section{REFERENCES}

1 Parfit D. Reason and persons. Oxford: Oxford paperbacks, 1986

2 Robertson S, Savulescu J. 'Is There a Case in Favour of Predictive Testing of Children?' Bioethics 2001;15:26-49. 